\title{
Lower prevalence of congenital cytomegalovirus infection in Portugal: possible impact of COVID-19 lockdown?
}

\author{
Catarina Fernandez ${ }^{1} \cdot$ Maria-Jesus Chasqueira ${ }^{1} \cdot$ Augusta Marques $^{1} \cdot$ Lúcia Rodrigues $^{1} \cdot$ Mónica Marçal $^{2}$. \\ Madalena Tuna ${ }^{2}$. Mónica Cró Braz ${ }^{3}$. Ana Serrão Neto ${ }^{3}$. Cândida Mendes ${ }^{4}$. David Lito ${ }^{4}$. Paula Rocha ${ }^{5}$. \\ Gabriela Vasconcellos ${ }^{5} \cdot$ Maria-Favila Menezes $^{6} \cdot$ Maria José Sousa $^{6} \cdot$ Carla Nunes $^{7} \cdot$ Paulo Paixão $^{1}$ (1)
}

Received: 16 March 2021 / Revised: 27 August 2021 / Accepted: 22 September 2021 / Published online: 30 September 2021

(c) The Author(s), under exclusive licence to Springer-Verlag GmbH Germany, part of Springer Nature 2021

\begin{abstract}
Cytomegalovirus (CMV) is the most frequent cause of congenital infection all over the world. Its prevalence ranges from 0.2 to $2.2 \%$. Transmission from children to their pregnant mothers is a well-known risk factor, particularly if they attend a childcare centre. This study aims to compare the prevalence of CMV congenital infection (CMV_CI) in Portugal (Lisbon) between two studies, performed respectively in 2019 and 2020. In the 2019 study, performed in two hospitals, we found a $0.67 \%$ CMV_CI prevalence, using a pool strategy previously tested with saliva samples. In the 2020 study, using the same pool approach in four hospitals (the previous and two additional), and based on 1277 samples, the prevalence was $0.078 \%$.

Conclusion: The close temporal coincidence with COVID-19 lockdown suggests that these measures may have had a significant impact on this reduction, although other explanations cannot be ruled-out.
\end{abstract}

\section{What is Known:}

- Cytomegalovirus is the leading cause of congenital infection.

- Behavioural measures decrease cytomegalovirus seroconversion in pregnant women.

What is New:

- From 2019 to 2020 there was a significant reduction in the prevalence of congenital CMV infection.

Keywords COVID-19 $\cdot$ CMV $\cdot$ Congenital $\cdot$ Screening $\cdot$ Pools

\author{
Abbreviations \\ CMV Cytomegalovirus \\ CMV_CI Cytomegalovirus Congenital Infection \\ DCC Day-Care Centers
}

Communicated by Nicole Ritz

Paulo Paixão

paulo.paixao@nms.unl.pt

1 Centro de Estudos de Doenças Crónicas, Faculdade de Ciências MédicasINOVA Medical School, CEDOC, Campo Mártires da Pátria, 130, 1169-056 Lisboa, Portugal

2 Unidade de Neonatologia-Serviço de Pediatria, Hospital São Francisco Xavier CHLO, Estrada Do Forte Do Alto Do Duque, 1449-005 Lisboa, Portugal

3 Serviço de Pediatria, Hospital CUF Descobertas, Rua Mário Botas, 1998-018 Lisboa, Portugal

\section{Introduction}

Cytomegalovirus (CMV) is an endemic virus, ubiquitous, species-specific for humans and member of the Herpesviridae family. This virus is the major cause of congenital infection disease worldwide. In utero transmission occurs in a range from 0.2 to $2.2 \%$, having a negative impact in morbidity and mortality [1].

4 Serviço de Pediatria, Hospital Vila Franca de Xira, Estrada Carlos Lima Costa no 2, 2600-009 Vila Franca de Xira, Portugal

5 Serviço de Pediatria, Hospital CUF Porto, Estrada da Circunvalação, 14341, 4100-180 Porto, Portugal

6 Centro de Medicina Laboratorial Germano de Sousa, Rua Cupertino de Miranda, 1600-513 Lisboa, Portugal

7 Centro de Investigação Em Saúde Publica, Escola Nacional de Saúde Pública, Universidade NOVA de Lisboa, Avenida Padre Cruz, 1600-560 Lisboa, Portugal 
When primoinfection occurs in pregnant women, the probability of transmission to the foetus varies between 30 and $40 \%$., with a higher risk of foetal disease when maternal infection occurs in the first 16 weeks. Not all congenitally infected children are symptomatic. In fact, just $10-15 \%$ will present symptoms, but 10 to $15 \%$ of the infants with no symptoms at birth will develop late sequels in the first five years of life, such as hearing loss, neurological, motor and visual impairment, among others [2]. Congenital CMV is now the major infectious cause of sensorineural hearing loss and neurodevelopmental abnormalities in infants born in developed countries [3].

Among young children with congenital infection, CMV shedding is lower among infants less than 1-year-old, but uniformly high among 1- and 2-year-old children. Thereafter, the shedding declines progressively, maintaining relatively high among 3-4-year-olds [4]. There are some reports that confirm the relation between high prevalence of CMV and day-care centers (DCC) [5]. In fact, children in large day-care group frequently acquire CMV infections from other children, and they will shed CMV in urine and saliva for extended periods of time as well. As a result of this, approximately $30 \%$ of mothers with a cytomegalovirus-infected child younger than 2 years old can seroconvert within 1 year after their child attending DCC [6].

Results from a few studies showed that behavioural measures, such as, body fluids contact avoidance from young children, reduced CMV seroconversion in pregnant women. These measures include avoiding contact with saliva when kissing young children, not sharing food, drinks or utensils used by them, or washing hands with soap and water for 15-20 s after changing nappies/diapers, feeding a young child, or wiping a young child's nose or saliva [3].

Another prevention strategy would be the vaccination against CMV. However, despite vaccine development is far advanced, with several candidate vaccines being already tested, vaccination is not yet available [7].

The effects of the COVID-19 lockdown on decreasing incidence of various communicable diseases in children have been discussed recently, but congenital CMV was not addressed [8]. Therefore, the aim of our study was to compare the 2020 prevalence of the congenital infection in four Portuguese hospitals (using a screening program with a pool strategy previously tested with saliva samples) [9], with the prevalence found in a 2019 cohort, before the pandemic period [10].

\section{Material and methodology}

\section{Population}

The study population of the current project included 1277 Portuguese newborns aged between one day and 10 days. They were born in Hospital CUF Descobertas $(n=349)$, Hospital Vila Franca de Xira $(n=301)$, Hospital S. Francisco
Xavier - CHLO $(n=380)$ and Hospital CUF Porto $(n=247)$. The samples were collected between June 3rd and November $11^{\text {th }}, 2020$. All newborns from these four hospital units were included, except when parental permission could not be obtained.

\section{Samples}

Saliva samples were collected using breakable rod rayon swabs (FLmedical, Torreglia, Italy), and was always carried out before breastfeeding or at least one hour after the last meal. The swab was packaged in a 3-mL tube with $750-\mu \mathrm{L}$ RPMI medium (Life Technologies, Paisley, UK). After collection, the tubes were stored at $4{ }^{\circ} \mathrm{C}$ until processing. When a positive result was obtained with a saliva sample, a urine sample was collected in the two first weeks of life to confirm congenital infection. These were collected using paediatric urine collection bags, then placed in 50-mL flasks and stored at $4{ }^{\circ} \mathrm{C}$ until processing.

All samples were sent to the laboratory of microbiology associated to Infection Unit of the Faculdade de Ciências MédicasINova Medical School (FCMINMS) for processing.

\section{Sample processing}

Sample processing is detailed elsewhere [9, 10]. Briefly, pools were prepared mixing $20 \mu \mathrm{L}$ of each 10 saliva samples in a $1.5 \mathrm{~mL}$ Eppendorf tube. Genomic DNA was extracted using the Purelink Genomic DNA commercial kit (Invitrogen, Carlsbad, USA), according to the manufacturer's instructions and stored at $-20{ }^{\circ} \mathrm{C}$ until use. HCMV DNA was amplified and detected by qPCR on the Applied Biosystems 7500 Fast Real-Time PCR System (Applied Biosystems, Foster City, USA) using an "in-house" method with $100 \%$ sensitivity and specificity when compared with individual samples.

\section{Previous study}

The details of the previous study are described elsewhere [10]. Briefly, the study was conducted for eight months (between October 2018 and May 2019), and involved 1492 newborns, aged between one day and two weeks, from Hospital CUF Descobertas $(n=748)$ and at Hospital Vila Franca de Xira $(n=744)$. There were 10 confirmed cases, corresponding to a prevalence of congenital CMV infection in the two participant hospitals of $0.67 \%$.

\section{Statistical methods}

- Confidence interval for proportions, using exact binomial method, for each study. 
Table 1 Punctual estimative and confidence intervals for both studies independently and in comparison between them

\begin{tabular}{lll}
\hline & $\begin{array}{l}\text { Punctual estima- } \\
\text { tive (\%) }\end{array}$ & 95\% Confidence intervals (\%) \\
\hline 2019 & 0.67 & $(0.32,-1.23)^{\mathrm{a}}$ \\
2020 & 0.078 & $(0.00,0.44)^{\mathrm{a}}$ \\
Comparison & -0.0059 & $(-0.01,-0.002)^{\mathrm{b}}$ \\
$2020-2019$ & & $(-0.0012,-0.0115)^{\mathrm{c}}$ \\
\hline
\end{tabular}

${ }^{\mathrm{a}}$ Exact binomial

${ }^{b}$ Normal distribution

${ }^{\mathrm{c}}$ Based on Newcombe combination method (9)

- $95 \%$ Confidence intervals for the difference between two proportions, using two different approaches: (1) Normal distribution; (2) based on Newcombe combination method [11].

\section{Results}

In the current study (2020), we grouped 1277 saliva samples into 129 pools of 10 samples each. Of these pools, 127 tested negative and two positives. After individual testing of each sample in the two positive pools, two positive saliva samples were identified.

Confirmatory urine samples showed that only one of the newborns had congenital infection, which represents an overall prevalence of $0.078 \%$.

Table 1 presents the punctual estimates and confidence intervals for both studies independently and comparison between them. We can observe a decrease of CMV_CI prevalence between 2019 and 2020, considering punctual estimate, from 0.67 to $0.078 \%$ in 2019 (more than 8 times higher than 2020). Looking to interval estimation for the difference between independent proportions, and based on the two different approaches, both intervals limits are negative, meaning that there is evidence that difference in CMV_CI prevalence is statistically significant.

In the 2020 study, and when considering only the results of the same two hospitals involved in the previous project [10], all the 650 tested samples were negative for CMV.

\section{Conclusion and discussion}

The range described in the literature for congenital CMV is usually low, from 0.2 to $2.2 \%$ [1]. However, during the current study, a much lower prevalence of CMV congenital infection was observed $(0.078 \%)$. This is a significant reduction when compared with the historic prevalence in Portugal (1.1\%) [12] and the results of our previous and similar study (0.67\%) [10]. Comparing with this late study, the strategy/methodology and two of the participant hospitals were the same although there were differences in length (8 months versus 5 months) and in the season, between the 2019 and the 2020 study. However, congenital CMV has no seasonal distribution or yearly variations [14], and therefore these factors must have had minimal, if any, impact on the results. Socio-demographic differences between the populations of the two studies are another possible explanation. However, the initial design of the study, aimed to test the pool strategy, did not include the analysis of this information.

Despite these potential confounding factors, a plausible explanation for this significant decrease could be the lockdown measures taken in Portugal due to the COVID-19 pandemic. In March 2020, children stopped attending DCC therefore decreasing the probability of CMV transmission to their mothers. Despite a progressive return of the children to DCC in September 2020, due to the beginning of the new school year, the worsening of the pandemic in October led many children back home. Thus, during the study period, many Portuguese children stayed at home most of the time.

This hypothesis is supported by current knowledge about the CMV epidemiology. In fact, it is widely accepted that pregnant women frequently acquire cytomegalovirus from other children, mainly those attending DCC [6], and recent data reinforce the role of young children on the epidemiology of CMV infections [13]. Additional information came from two cluster randomised trials and one singlegroup study, showing that behavioural measures that reduce contact with bodily fluids from young children decreases cytomegalovirus seroconversion in pregnant women [3]. Although the COVID-19 lockdown measures are obviously transitory and therefore without practical application for a future prevention strategy, the results of the current study are in line with the important role that non-pharmaceutical interventions may play in the prevention of the CMV congenital infection. However, the current study was not controlled to assess the effect of the lockdown on the incidence of congenital CMV infection, and therefore any explanation for this reduction remains speculative.

In conclusion, our results showed a significant decrease in the prevalence of congenital CMV infection between 2019 and 2020. The temporal coincidence with COVID19 lockdown suggests that these measures may have had a significant impact on this reduction, but other explanations cannot be excluded. Additional studies are warranted for definitive clarification.

Acknowledgements We thank all the parents who allowed the harvest of biological samples to their children. 
Authors' contributions CF: material preparation, data analysis, draft of the manuscript and approval of the final manuscript; MJC: supervision in the analysis of the results, critical revision of the manuscript and approval of the final manuscript; AM and LR: material preparation, technical supervision and approval of the final manuscript; MM, MCB, CM, DL, PR and GV: data collection and approval of the final manuscript; MT, ASN: critical revision of the manuscript and approval of the final manuscript; MFM and MJS: organization of the sample collection, critical revision of the manuscript and approval of the final manuscript; $\mathrm{CN}$ : statistical analysis and revision of the manuscript; PP: designed the study concept, review and editing of the manuscript and approval of the final manuscript.

Funding This work was supported by a research grant from Merck Sharp \& Dohme Corp., a division of Merck \& Co., Inc., Kenilworth, NJ, USA [IIS\# 59301].

Availability of data and material The datasets used and/or analysed during the current study are available from the corresponding author on request.

\section{Declarations}

Ethics approval and consent to participate The study was approved by the ethics committees of four participant hospitals. Written informed consent was obtained from a parent for their newborn's enrolment in the study.

\section{Consent for publication N/A}

Conflict of interest The authors declare no competing interests.

\section{References}

1. Dreher AM, Arora N, Fowler KB, Novak Z, Britt WJ, Boppana SB, Ross SA (2014) Spectrum of disease and outcome in children with symptomatic congenital cytomegalovirus infection. J Pediatr 164(4):855-9. https://doi.org/10.1016/j.jpeds.2013.12.007. Epub 2014 Jan 14. PMID: 24433826; PMCID: PMC3982912

2. Emery VC, Lazzarotto T (2017) Cytomegalovirus in pregnancy and the neonate. F1000Res 6:138. https://doi.org/10.12688/f1000research. 10276.1. PMID: 28299191; PMCID: PMC5310379

3. Rawlinson WD, Boppana SB, Fowler KB, Kimberlin DW, Lazzarotto T, Alain S, Daly K, Doutré S, Gibson L, Giles ML, Greenlee J, Hamilton ST, Harrison GJ, Hui L, Jones CA, Palasanthiran P, Schleiss MR, Shand AW, van Zuylen WJ (2017) Congenital cytomegalovirus infection in pregnancy and the neonate: consensus recommendations for prevention, diagnosis, and therapy. Lancet Infect Dis 17(6):e177-e188.
https://doi.org/10.1016/S1473-3099(17)30143-3. Epub 2017 Mar 11 PMID: 28291720

4. Cannon MJ, Hyde TB, Schmid DS (2011) Review of cytomegalovirus shedding in bodily fluids and relevance to congenital cytomegalovirus infection. Rev Med Virol 21(4):240-55. https:// doi.org/10.1002/rmv.695. Epub 2011 Jun 15. PMID: 21674676; PMCID: PMC4494736

5. Zheng QY, Huynh KT, van Zuylen WJ, Craig ME, Rawlinson WD (2019) Cytomegalovirus infection in day care centres: a systematic review and meta-analysis of prevalence of infection in children. Rev Med Virol 29(1):e2011. https://doi.org/10.1002/rmv.2011. Epub 2018 Oct 10. PMID: 30306730

6. Marshall BC, Adler SP (2009) The frequency of pregnancy and exposure to cytomegalovirus infections among women with a young child in day care. Am J Obstet Gynecol 200(2):163.e1-5. https://doi.org/10.1016/j.ajog.2008.08.037. Epub 2008 Oct 9. PMID: 18845286; PMCID: PMC2662485

7. Plotkin SA, Boppana SB (2019) Vaccination against the human cytomegalovirus. Vaccine 37(50):7437-7442. https://doi.org/10. 1016/j.vaccine.2018.02.089

8. Belingheri M, Paladino ME, Piacenti S, Riva MA (2021) Effects of COVID-19 lockdown on epidemic diseases of childhood. J Med Virol 93(1):153-154. https://doi.org/10.1002/jmv.26253

9. Silva J, Fernandes C, Marques A, Maria AT, Correia C, Tuna ML, Chasqueira MJ, Paixão P (2020) Evaluation of saliva pools method for detection of congenital human cytomegalovirus infection. $\mathrm{J}$ Virol Methods 275:113759. https://doi.org/10.1016/j.jviromet.2019. 113759. Epub 2019 Oct 31 PMID: 31678048

10. Fernandes C, Marques A, de Jesus Chasqueira M et al (2021). Saliva pools for screening of human cytomegalovirus using realtime PCR. Eur J Pediatr 180:1067-1072. https://doi.org/10.1007/ s00431-020-03842-x

11. Newcombe RG (1998) Interval estimation for the difference between independent proportions: comparison of eleven methods. Stat Med 17(8):873-890

12. Paixāo P, Almeida S, Gouveia P, Vilarinho L, Vaz OR (2009) Prevalence of human cytomegalovirus congenital infection in Portuguese newborns. Euro Surveill 14(9):13-15. PMID: 19317972

13. Leruez-Ville M, Guilleminot T, Stirnemann J, Salomon LJ, Spaggiari E, Faure-Bardon V, Magny JF, Ville Y (2020) Quantifying the burden of congenital cytomegalovirus infection with long-term sequelae in subsequent pregnancies of women seronegative at their first pregnancy. Clin Infect Dis 71(7):1598-1603. https://doi.org/10.1093/cid/ ciz1067. PMID: 31665306

14. Boppana SB, Fowler KB (2007) Persistence in the population: epidemiology and transmisson. In: Arvin A, Campadelli-Fiume G, Mocarski E, Moore PS, Roizman B, Whitley R, Yamanishi K, editors. Human Herpesviruses: Biology, Therapy, and Immunoprophylaxis. Cambridge: Cambridge University Press. Chapter 44. pp 795-813

Publisher's Note Springer Nature remains neutral with regard to jurisdictional claims in published maps and institutional affiliations. 